Bangladesh Journal of Anatomy January 2014, Vol. 12, No. 1 pp. 17-21

\title{
Sexual Dimorphism in Alar Length and Auricular Index of Sacrum
}

\author{
AHM Mostafa Kamal' ${ }^{1}$, Shamim Ara², Shahanaz Begum ${ }^{3}$, Md. Mesbahul Hoque, \\ Khadeza Khatun ${ }^{5}$
}

\begin{abstract}
Context : It has long been customary among anatomists, anthropologists and forensic experts to judge the sex of the skeletal material by non-metric observations. Afterward the study of sexual divergence has been based upon actual measurements in different bones. The study in relation to metrical data on bone is very few in our country. The study was planned to observe the differences of sacra between male and female in respect to measurement of alar length and auricular index of sacrum. The findings of this study might be useful in providing morphometrical data that can be used by anatomists, forensic experts, anthropologists, orthopedic surgeons and neurologists for proper initiative in their respective fields.
\end{abstract}

Materials and Methods: A cross-sectional, analytical type of study was performed in the department of Anatomy, Dhaka Medical College, Dhaka from January 2011 to December 2011. A total of 172 (one hundred seventy two) adult human dry sacra of unknown sex was assessed. The study samples were distributed in male and female sex groups by discriminant function analysis. All the samples were studied morphologically. Length of ala and auricular surface were measured with the help of digital slide calipers.

Results: The mean length value of ala was greater in female than male $(P<0.001)$. The difference between the mean value of alar index in male and female was significant $(P>0.05)$. The mean value of auricular index was higher in male than female and the difference was statically significant $(P<0.001)$.

Conclusion: The sacrum can be used for sexual dimorphism as is usual in anthropological work. The knowledge of alar length and auricular index of sacrum is essential in medico-legal practice for sex determination of an individual.

Key words : Sacrum, ala, auricular surface, auricular index, sexual dimorphism.

\section{Introduction}

The sacrum is a triangular irregular type of bone, situated in the lower part of the vertebral column and at the upper and back part of the pelvic cavity ${ }^{1}$. The transverse process of sacrum is formed by the fusion of the transverse process and the costal elements to each other and to the rest of the vertebra, and forms the upper surface of the sacral lateral mass or ala².

1. Assistant Professor, Department of Anatomy. Dhaka Medical College, Dhaka.

2. Professor and Head, Department of Anatomy, Dhaka Medical College, Dhaka.

3. Professor and Head, Department of Anatomy, NICVD, Shere-E-Bangla Nagar, Dhaka-7.

4. Assistant Professor, Department of Anatomy, Satkhira Medical College, Satkhira.

5. Lecturer, Department of Microbiology . Dhaka Medical College, Dhaka.

Correspondence : Dr. AHM Mostafa Kamal
Anatomical variations occur frequently in the lower region of the vertebral column, making the sacrum the most variable portion of the vertebra. The variation may be attributed to the dependency of the final sacral morphology to the load-related fusion of the bone structure ${ }^{3}$. The bones of the body are the last to pass away after death, next to enamel of teeth. Hence, in establishing the personal identity with respect to sex, age and stature, medico legal experts, anatomist and anthropologist use the skeletal materials for giving their opinion 4 . Worldwide, various studies have been conducted on the determination of sex from variety of human bones i.e. skull, pelvis, long bones, scapula, clavicle, and the bones like metatarsals, metacarpals, phalanges, patella, vertebrae, ribs etc. The most popular statistical model in sex determination is recently developed discriminant 
function analysis which encouraged many forensic scientists to assess their anthropometric data ${ }^{5}$. Correct classification estimates for the discriminant function range from $66-72 \%{ }^{6}$. The high accuracy of sex assessment $(88.3 \%)$ by the discriminant analysis of the sacral base is a valid method of estimating the sex of skeletal remains from a range of populations. A discriminant function analysis of the three variables of first sacral vertebra produced a prediction accuracy of $92.1 \%$.

The identification of sex in human skeletal remains an important component of many forensic investigations and should be based on measurements and observations on the entire skeleton to be meaningful ${ }^{8}$. Sacrum is an important bone for identification of sex in human skeletal system. Since it is a component of axial skeleton and because of its contribution to the pelvic girdle and in turn to the functional differences in the region between the sexes, it has an applied importance in determining sex with the help different of measurements carried upon it ${ }^{9}$.

A positive correlation was observed between the length of auricular surface and length of sacrum. Baptist ${ }^{10}$ stated that it is an important bone in the teaching of sex differences. There is a certain corelation between the length of the sacrum and its auricular surface. Therefore, the sex determination can be statistically confirmed after evaluation of these two parameters. Sex-dependent differences have been noted in the pelvic bone anatomy, and so it follows that differences exist in the male and female sacrum ${ }^{11}$. Different measurement including alar length and auricular length of the sacrum shows variations among male and female. So it can be used for sexual dimorphism as is usual in anthropological work ${ }^{12}$. The knowledge of length of ala and auricular index of sacrum is essential in medico-legal practice for age, sex and race determination of an individual.

\section{Materials and Methods}

A total of 172 (one hundred seventy two) dry completely ossified, grossly normal adult human sacra of unknown sex was assessed. The sacra were collected from Department of Anatomy of Dhaka Medical College, Sir Salimullah Medical College and Shaheed Suhrawardy Medical College, Bangladesh Medical College, Medical College for Women and Hospital, Ibrahim Medical College and M H Somorita Medical College, Dhaka. The study samples were distributed in male and female sex groups by discriminant function analysis. With the help of digital slide caliper different measurements were recorded in millimeters. Length of ala was measured by the distance taking by one point on lateral most point of superior surface of body of first sacral vertebra and another point on lateral most part of ala (Fig- 1$)^{10}$. Maximum length of auricular surface was measured by taking one point on the upper most part of auricular surface and another point on the lower most part of auricular surface of sacrum (Fig.-II) ${ }^{13}$.

By using the above measurements the following indices $^{13,14}$ were calculated.

\section{Alar Index:}

Alar Index $=\frac{\text { Length of each Ala }}{\text { Transverse diameter of body of }} \times 100$

\section{Auricular Index:}

$\begin{aligned} & \text { Auricular } \\ & \text { Index }\end{aligned}=\frac{\text { Length of Auricular Surface }}{\text { Breadth of Sacrum }} \times 100$

A comparison of the mean values between sexes was performed using the unpaired Student's't'-test, $p$-value $<0.05$ was considered statistically significant.

\section{Ethical Clearance}

This study was approved by the Ethical Review Committee of Dhaka Medical College, Dhaka.

\section{Results}

The mean length value of ala was greater in female than male $(P<0.001)$. Irrespective of side the mean length of the sacral auricular surface was greater in male than female and it was found statistically significant $(P<0.001)$. After data collection, 
processing and analysis, the following observations were obtained :

Table-I shows that the mean length of right and left side of ala was $28.62 \pm 2.99 \mathrm{~mm}$ and $28.35 \pm 3.58$ $\mathrm{mm}$ in male and $29.27 \pm 3.47 \mathrm{~mm}$ and $29.11 \pm 3.54$ $\mathrm{mm}$ in female respectively. The difference between right and left side was not statistically significant $(P>0.05)$. Irrespective of sides the mean length of ala was greater in female than male $(P<0.001)$.

Table- I

Length of the right and left side of ala in male and female.

\begin{tabular}{lccl}
\hline & \multicolumn{2}{c}{ Length of ala $(\mathrm{mm})$} & \\
& Right side & Left side & $P$ value \\
& Mean \pm SD & Mean \pm SD & \\
\hline Male & $28.62 \pm 2.99$ & $28.35 \pm 3.58$ & $>0.05^{\text {ns }}$ \\
$(\mathrm{n}=55)$ & $(25.63-31.61)$ & $(24.77-31.93)$ & \\
Female & $29.27 \pm 3.47$ & $29.11 \pm 3.54$ & $>0.05^{\text {ns }}$ \\
$(\mathrm{n}=66)$ & $(25.80-32.74)$ & $(25.57-32.65)$ & \\
$P$ value & $<0.001^{\star \star \star}$ & $<0.001^{\star \star \star}$ & \\
Total & $28.97 \pm 3.26$ & $28.76 \pm 3.57$ & $>0.05^{\text {ns }}$ \\
$(\mathrm{n}=121)$ & $(25.71-32.23)$ & $(25.19-32.33)$ & \\
\hline
\end{tabular}

Figure in parentheses indicates range. Comparison between right and left side done by paired Student's ' $\mathrm{t}$ ' test and comparison between sex done by unpaired Student's 't' test, ns =not significant, $* / * \star / * \star *=$ significant.

Table-II shows that the length of right and left sacral auricular surface was $56.65 \pm 6.24 \mathrm{~mm}$ and $57.05 \pm 6.08 \mathrm{~mm}$ in male and $52.35 \pm 5.75 \mathrm{~mm}$ and $51.55 \pm 5.76 \mathrm{~mm}$ in female respectively. The difference between right and left side was not statistically significant $(P>0.05)$. Irrespective of side the mean length value of the sacral auricular surface was greater in male than female $(\mathrm{P}<0.001)$.

The alar index and auricular index was found $65.65 \pm 11.84$ and $54.26 \pm 5.56$ in male and $65.14 \pm 9.11$ and $50.02 \pm 5.21$ in female respectively
(Table-III). The difference between the mean value of alar index in male and female was isignificant $(P>0.05)$. The mean value of auricular index was higher in male than female and the difference was statically significant $(P<0.001)$.

Table -II

Length of sacral auricular surface in male and female

\begin{tabular}{|c|c|c|c|}
\hline \multicolumn{4}{|c|}{ Length of sacral auricular surface (mm) } \\
\hline Sex & 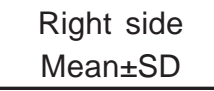 & $\begin{array}{l}\text { Left side } \\
\text { Mean } \pm S D\end{array}$ & $\begin{array}{c}P \\
\text { value }\end{array}$ \\
\hline Male & $56.65 \pm 6.24$ & $57.05 \pm 6.08$ & $>0.05^{\mathrm{ns}}$ \\
\hline$(n=91)$ & $(50.41-62.89)$ & $50.97-63.13$ & \\
\hline Female & $52.35 \pm 5.75$ & $51.55 \pm 5.76$ & $>0.05^{\text {ns }}$ \\
\hline$(n-81)$ & $(46.60-58.10)$ & $(45.79-57.31)$ & \\
\hline$P$ value & $<0.001^{\star \star *}$ & $<0.001^{\star \star \star}$ & \\
\hline Total & $54.63 \pm 6.37$ & $54.65 \pm 6.44$ & $>0.05^{\mathrm{ns}}$ \\
\hline$(n=172)$ & $(48.26-61.00)$ & $(48.21-61.09)$ & \\
\hline
\end{tabular}

Figure in parentheses indicate range. Comparison between right and left done by paired Student's ' $\mathrm{t}$ ' test and comparison between sex done by unpaired Student's 't' test, $\mathrm{ns}=$ not significant, ${ }^{* / * * / * *}=$ significant

Table -III

Alar Index and Auricular Index in male and female

\begin{tabular}{lcc}
\hline Sex & $\begin{array}{c}\text { Alar Index } \\
(\text { Mean } \pm \text { SD) }\end{array}$ & $\begin{array}{c}\text { Auricular Index } \\
(\text { Mean } \pm \text { SD) }\end{array}$ \\
\hline Male & $65.65 \pm 11.84$ & $54.26 \pm 5.56$ \\
$(\mathrm{n}=91)$ & $(31.38-81.88)$ & $(40.79-65.78)$ \\
Female & $65.14 \pm 9.11$ & $50.02 \pm 5.21$ \\
$(\mathrm{n}=81)$ & $(35.62-87.65)$ & $(37.58-68.29)$ \\
$\mathrm{t}$ & 0.315 & 4.29 \\
$P$ value & $0.753^{\mathrm{ns}}$ & $0.001^{\text {** }}$ \\
\hline
\end{tabular}

Figure in parentheses indicate range. Comparison between sex done by unpaired Student's ' $\mathrm{t}$ ' test,

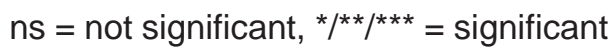




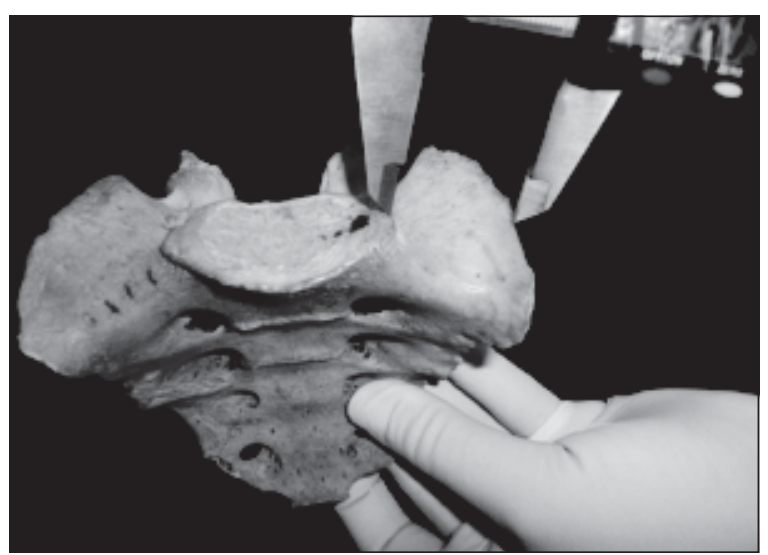

Fig.-1: Photograph showing the measurement of length of ala by using digital slide caliper.

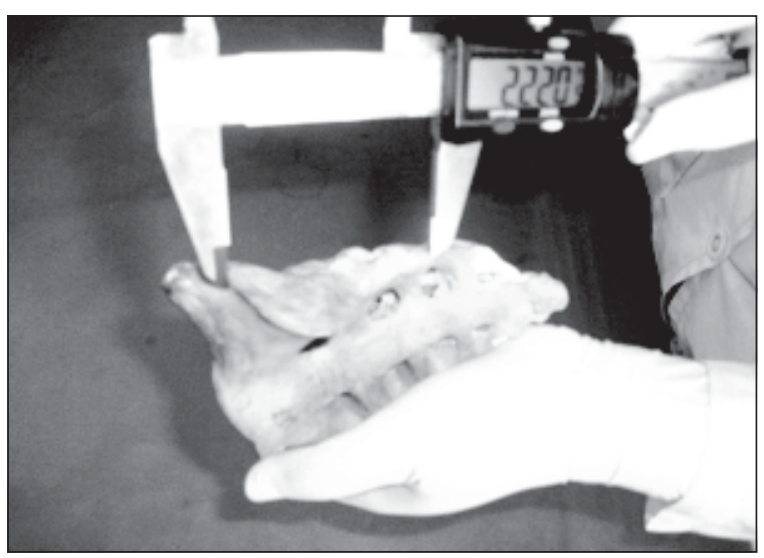

Fig.-2: Photograph showing the measurement of the maximum length of auricular surface by using digital slide caliper.

\section{Discussion}

The mean $( \pm S D)$ length of right and left side of ala was found $28.62 \pm 2.99 \mathrm{~mm}$ and $28.35 \pm 3.58 \mathrm{~mm}$ in male and $29.27 \pm 3.47 \mathrm{~mm}$ and $29.11 \pm 3.54 \mathrm{~mm}$ in female respectively. The difference between right and left side was not statistically significant $(P$ $>0.05$ ). Irrespective of sides the mean length of ala was greater in female than male and it was found statistically significant $(P<0.001)$. Various measurements of sacra of Agra region were taken by Mishra, et al ${ }^{13}$ and they found that mean length of ala was $28.38 \mathrm{~mm}$ in male which was similar to present study and $31.67 \mathrm{~mm}$ in female which was not similar to the findings of the present study.

In this present study the mean ( $\pm S D$ ) length of right and left sacral auricular surface was $56.65 \pm 6.24 \mathrm{~mm}$ and $57.05 \pm 6.08 \mathrm{~mm}$ in male and $52.35 \pm 5.75 \mathrm{~mm}$ and $51.55 \pm 5.76 \mathrm{~mm}$ in female respectively. Irrespective of side the mean length of the sacral auricular surface was greater in male than female and it was found statistically significant $(P<0.001)$ and the findings of present study was similar to the findings of Mishra, et al ${ }^{13}$. Baptist ${ }^{12}$ observed that mean values of all parameters of sacra were higher in males than in females. Analysis of the differences in the mean values of males and females were also undertaken and studied statistically. Among the males, the mean of the auricular length of sacrum was more than in the females and the difference was statistically significant $(P<0.05)$.

The mean $( \pm S D$ ) value of alar index and auricular index was found $65.65 \pm 11.84$ and $54.26 \pm 5.56$ in male and $65.14 \pm 9.11$ and $50.02 \pm 5.21$ in female respectively. The difference between alar index in male and female was isignificant $(P>0.05)$. The auricular index was higher in male than female and the difference was statistically significant $(P<0.001)$. The mean auricular index more in males than females was observed by Mishra et $\mathrm{al}^{13}$ and the difference was statistically highly significant $(P<0.001)$. So, sexual dimorphism was observed in the mean values of auricular index in different studies.

\section{Conclusion}

The present study showed that the mean length value of ala was greater in female than male $(P<0.001)$. Irrespective of side the mean length of the sacral auricular surface was greater in male than female and it was found statistically significant $(P<0.001)$. The auricular index was higher in male than female and the difference was statically significant $(P<0.001)$. The present study therefore revealed that for sexing of sacrum, the reading obtained by alar length and auricular index of sacrum were relevant and more significant.

\section{References}

1. Newell RLM. Osteology. S. Standring, ed. 2008. Gray's Anatomy The Anatomical Basis of Clinical Practice. Paris: Churchill Livingston 2008: 724-28.

2. Snell RS. Clinical Anatomy by Region. $8^{\text {th }}$ ed. USA: Lippincott \& Wilkins 2008: 310-16. 
3. Mehta S, Joshua D, Auerbach M.D, Christopher T, Born MD, Kingsley R, Chin MD. Sacral fractures. J Am Acad Orthop Surg 2006; 14(12): 656-65.

4. Math SC. Sexual dimorphism in sacrum. M.S. Rajiv Gandhi University of Health Sciences, Karnataka, Bangalore 2006: 59-69.

5. Krishan K. Anthropometry in forensic medicine and forensic science-'forensic anthropometry'. The Internet Journal of Forensic Science 2007: 2(1): 1-12.

6. Plochocki JH. Sexual dimorphism of anterior sacral curvature. Journal of Forensic Sciences 2011; 56(1) : 161-64.

7. Benazzi S, Maestri C, Parisini S, Vecchi F, Gruppioni G. SexAssessment from the Sacral Base by Means of Image Processing. Journal of Forensic Sciences 2009; 54(2): 249-54

8. Stewart T D. The vertebral column of the Eskimo. American journal of Physical Anthropology 1932; 17: 123-36.
9. Patel MM, Gupta BD and Singel TC. Sexing of sacrum by sacral index and kimura's basewing index, Jiafm 2005; 27(1): 971-73.

10. Baptist M, Sultana F, Farzana F. Sex differences in sacra in the Punjab region. Biomedica 2008; 24 (23): 152-57.

11. Cheng JS, Song JK. Anatomy of the Sacrum. Neurosurg Focus 2003; 15(2): 1-9.

12. Arora KA, Gupta P, Mahajan S, Kapoor SS. Significance of sacral index in estimation of sex in sacra of cadavers in Punjab. J Indian Acad Forensic Med 2008; 32(2): 104.

13. Mishra SR, Singh PJ, Agrawal AK, Gupta RN. Identification of sex of sacrum of agra region. J Anat. Soc. India 2003; 52(2): 132-36 .

14. Maddikunta V, Ravinder N. Role of Morpho Metrical Data of Sacrum in Determination of Sex. Int J Biol Med Res 2014; 5(1): 3785-92. 